\title{
Pig Surgery: Can Reduction Be a Protocol Violation?
}

"Swine Are Fine" read the sign hanging over Dr. Giorgio Bertucci’s desk. An experienced cardiovascular researcher, Bertucci had been working with swine models for nearly 30 years. "Of course," he said, "it was a lot less expensive back then. The cost of buying a pig was next to nothing because they came from local farms. And the per diem cost was much less than it is today. Now I have fancy, research-bred pigs that cost me hundreds of dollars for each one, and on top of that I have to pay an ordering fee, a shipping fee, a veterinary exam fee for an animal that's healthy, and a per diem fee that could feed my family for a week. On top of that I have to deal with an IACUC that tells me I can't do this or that to an anesthetized animal that's never going to recover from surgery. My Lord, what is happening?"

"Well, I can't say as I disagree" said his colleague, Dr. Anton Spinoza. "I mean, I haven't been doing this as long as you, but it quickly eats up your grant money." "You know," he said, "I have an idea. Since we're both doing nonsurvival surgery with pigs, and since we both have approved protocols for different parts of the body, why don't we just use the same pig?" "Sounds good to me" said Bertucci. "The IACUC should be happy that we're using fewer animals."

They did what they said they were going to do, and, needless to say, the incident worked its way back to the IACUC. Peter Stone, the IACUC Chairman, was relating the incident to George Lockridge, the Committee's Vice-Chair. "George, if those two guys would have just amended their protocols, there wouldn't be any issue. And I'll tell you something else; if it were survival surgery it wouldn't be the problem that it is because it would be a clear-cut protocol violation. This one is tricky because even though their motivation was just to save money, they wound up saving the money and using one less pig. But they did procedures on one pig that we approved for two separate animals. I can't tell if it was because of sheer luck or good technique that everything went smoothly and they got the data they needed. To tell you the truth, I don't know if I should hang them or hug them. What do you think I should do?" "Well," said Lockridge, "I'll tell you what I would do. I would pull those guys aside and tell them not to do anything like that again without amending their protocols, and then I would drop the issue. There was no harm done to the animals, and there's no need to turn everything into a federal case. Remember, these were both terminal studies. Just give them an off-therecord 'heads-up', and forget about it."

Do you think Lockridge was giving Stone rational advice, or does the IACUC Chair have to do more with this alleged protocol violation?

\section{Creative Thinking} Steven M. KuhIman, VMD, DACLAM

All right, Lockridge!! You're headed in the right direction. The simple solution is to reproach Bertucci and Spinoza, make them submit an amendment, and tell them not to repeat their behavior. However, is that what the law requires? The Animal Welfare Act Regulations require an amendment for significant changes to ongoing animal activity. Does using fewer animals constitute a significant change? Are investigators who don't use the specified number of animals originally requested required to amend their protocols? If not, why would an amendment be necessary in this case?

The regulations do not define "significant" changes regarding the care and use of animals in ongoing activities. However, they do define a significant deficiency as one that, with reference to Subchapter A, and, in the judgment of the IACUC and the Institutional Official (IO), is or may be a threat to the health or safety of the animals ${ }^{1}$. If that standard were applied to this case, then an amendment would be necessary for changes that may have a negative impact on the care and use of the animals. There has been no negative impact on the animal.

The website for the Intramural Animal Care and Use (ACU) program of the National Institutes of Health (NIH) states that amendments typically cover issues such as requests for "[a] change in the overall aims or objectives of the study; a change which may involve an increase in the levels of pain, distress, and/or discomfort; a change from non-surgery to surgery, from minor to major surgery, from nonsurvival to survival surgery, or from single to multiple survival surgery; an increase in the approximate number of animals used; a change in the genus or species of animals used; a change in the principal investigator [on the protocol]; or the addition of the use of hazardous agents in animal procedures $^{2}$." The site acknowledges that this list is not comprehensive. Most of the changes listed have the potential for a negative impact on the care and use of the animals. There was no negative impact on the ani$\mathrm{mal}$ in the hypothetical scenario.

If the actions of the two investigators are in support of the 3Rs of Russell and Burch and not in violation of the regulations, then there should be support and encouragement for their actions. They were able to reduce the number of animals used and still achieve their experimental objectives. It should not concern anyone that part of the motivation was economic, considering that 
there was no additional pain or distress for the animal. The issue of cost drives many improvements to processes. Rather than unofficially reprimanding these two researchers, they should be encouraged to continue creative thinking. They were right to assume that the IACUC would be happy that they're using fewer animals.

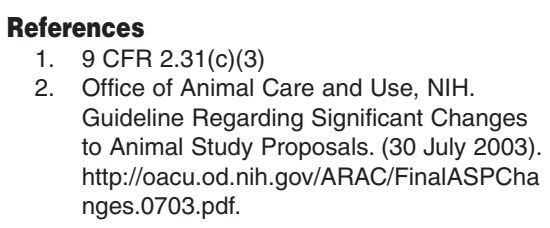

2. Office of Animal Care and Use, $\mathrm{NIH}$. Guideline Regarding Significant Changes to Animal Study Proposals. (30 July 2003). http://oacu.od.nih.gov/ARAC/FinalASPCha nges.0703.pdf.

Kuhlman is the Head of Veterinary Surgical Services at Pfizer Inc., Kalamazoo, MI.

\section{A Pig in Time Saves Nine}

\section{Lori R. Hill, DVM, DACLAM and Torsten Hopp PhD}

It seems that the researchers in this scenario were well meaning in that they were, in fact, practicing the 'reduction' component of the 3Rs by making more extensive use of one animal rather than using two. Doing multiple terminal procedures on a single animal can maximize the use of animals as a means of reduction ${ }^{1}$. In addition, both of the researchers reached their objectives without causing further pain or distress to the animal. According to the scenario, it seems that Bertucci and Spinoza did not knowingly commit a protocol violation. In fact, all procedures were already approved, just not under one protocol umbrella. In our opinion, however, the objective of cost reduction alone is not a valid justification.

There is a fairly straightforward way that this problem could have been avoided. The researchers could have added each other and any other manipulators to one another's protocols. In addition, they could have briefly described their use of one animal for both protocols and each referenced the other protocol. The USDA category would not change because both were doing terminal procedures. The IACUC would probably not have considered these types of changes to be substantive and might have approved them administratively, in a timely manner ${ }^{1-3}$.

There is still the question of under which of the two protocols the animals would be purchased, housed and manipulated, and how they should be counted. One should count the animals only once, regardless of the number of proposals in which they were used ${ }^{1,4}$. If both protocols were amended to reference all potential procedures and manipulators, we would have suggested that the researchers alternate in using their respective protocols. This situation obviously does not allow the transfer of animals from one protocol to the other.

We are inclined to suggest a solution similar to that of Lockridge by requiring that both researchers amend their protocols to cover the combination of procedures and manipulators. Because the animal was not subjected to further pain and distress, and all procedures were approved (albeit under separate protocols), that amendment of the protocols would be sufficient. The USDA, APHIS Animal Care Policy \#17, specifically discusses the use of animals on more than one protocol ${ }^{4}$.

The issue of whether this situation is a 'federal case' (i.e., reportable) seems clearcut. The PHS Policy states that the IACUC, through the IO, must report to OLAW "serious or continuing non-compliance with [PHS] Policy, any serious deviation from the provisions of the Guide, or any suspension of an activity by the IACUC 5 ." The Animal Welfare Regulations only require reporting to APHIS when an activity is suspended ${ }^{6}$. The scenario described in this column does not fulfill any of the requirements for reporting.

The Great Eastern IACUC needs to develop a policy for the use of animals on multiple protocols. The existence of such a policy to educate investigators could have avoided the scenario described here .

\footnotetext{
References

1. Silverman, J., Suckow, M.A. \& Murthy, S., eds. The IACUC Handbook (CRC Press,
}

Boca Raton, FL, 2000).

2. Wolff, A., Garnett, N., Potkay, S., Wigglesworth, C., Doyle, D. \& Thornton, V. Frequently asked questions about the Public Health Service Policy on Humane Care and Use of Laboratory Animals. Lab Anim. (NY) 24(9), 33-36 (2003).

3. National Institutes of Health. Office of Extramural Research. Revised Guidance Regarding IACUC Approval of Changes in Personnel Involved in Animal Activities. Notice: NOT-OD-03-046 (6 June 2003).

4. USDA APHIS. Animal Care Policy \#17, Annual Report for Research Facilities (17 March 1999).

5. Public Health Service. Public Health Service Policy on Humane Care and Use of Laboratory Animal IV.F.3 (US Department of Health and Human Services, Washington, DC, 1986).

6. 9 CFR, Part 2, Subchapter A, Regulations.

Hill is Institutional Veterinarian and Hopp is IACUC Administrator, Baylor College of Medicine, Houston, TX.

\section{Don't Cross That Line!}

Markus Josten, Dr. med. vet.

To make their lives a little bit easier, two scientists have changed their protocols. "Easy" in this context means "cheaper", because they agreed on using one pig where, according to the protocols, they should have used two. From the 3R's standpoint, they have reached the very desirable goal of using the smallest number of animals possible in animal experimental work. From their point of view it is an issue of nonsurvival surgery, and one could even have some sympathy for their idea of pig sharing, with both of them using different organs of a single animal that will not recover from this procedure anyway. However, there are certain rules in our world, and they exist not solely to make our lives more difficult or complicated, as they sometimes seem to do. It is the initial intention of these rules to provide a clear framework in which we can live our lives. It is obligatory for everyone to stay inside these boundaries, because the freedom of the one comes to an end where the freedom of the other is affected. As a matter of fact, we might sometimes come close to the 